\title{
The aerobic oxidation of alcohols with a ruthenium porphyrin catalyst in organic and fluorinated solvents
}

\author{
Vasily N. Korotchenko, ${ }^{a}$ Kay Severin ${ }^{b}$ and Michel R. Gagné ${ }^{* a}$ \\ Received 14th January 2008, Accepted 26th March 2008 \\ First published as an Advance Article on the web 14th April 2008 \\ DOI: $10.1039 / \mathbf{b 8 0 0 5 8 3 d}$
}

Carbonylruthenium tetrakis(pentafluorophenyl)porphyrin $\mathrm{Ru}(\mathrm{TPFPP})(\mathrm{CO})$ was utilized for the aerobic oxidation of alcohols. The in situ activation of the catalyst with mCPBA provided a species capable of catalyzing the oxidation of alcohols with molecular oxygen. The choice of solvent and additive was crucial to obtaining high activity and selectivity. Secondary aromatic alcohols were oxidized in the presence of the ruthenium porphyrin and tetrabutyl ammonium hydroxide in the solvent bromotrichloromethane, enabling high yields to be achieved (up to $99 \%$ ). Alternatively, alcohols could be oxidized in perfluoro(methyldecalin) with the ruthenium porphyrin at higher temperatures $\left(140{ }^{\circ} \mathrm{C}\right)$ and elevated oxygen pressures (50 psi).

\section{Introduction}

The oxidation of an alcohol to a carbonyl compound is an important transformation, and although there are many different methods for such functional group manipulations, catalytic procedures that are environmentally friendly, atom efficient, and occur under aerobic conditions, are significantly less common. The use of molecular oxygen as a stoichiometric oxidant is very attractive since innocuous byproducts result $\left(\mathrm{H}_{2} \mathrm{O}\right.$ or $\left.\mathrm{H}_{2} \mathrm{O}_{2}\right) .{ }^{1}$ Modern, metal-catalyzed aerobic oxidation of alcohols has recently been reviewed, ${ }^{2,3}$ and these reviews outline significant progress in the elaboration of homogeneous and/or heterogeneous catalysts in general, and in ruthenium catalysts in particular. ${ }^{4,5}$ Since Groves' pioneering discovery of the aerobic epoxidation of olefins catalyzed by the cytochrome P450 analog dioxo(tetramesitylporphyrinato)ruthenium, ${ }^{6}$ numerous investigations have focused on aerobic and anaerobic oxidative transformations catalyzed by ruthenium porphyrin complexes. ${ }^{7}$ Although Hirobe $^{8}$ and Groves 9 have reported high turnover numbers (TONs) using 2,6-disubstituted pyridine- $N$-oxides as the stoichiometric oxidant, similarly effective aerobic oxidations of alcohols remain largely unreported..$^{10,11}$

\section{Results and discussion}

We recently prepared an immobilized $\mathrm{Ru}$ (meso-tetraarylporphyrin) complex and investigated its catalytic activity in the epoxidation of olefins and oxidation of alcohols and alkanes using 2,6-dichloropyridine- $N$-oxide. ${ }^{12}$ Unfortunately, our attempts to utilize this catalyst to mediate oxidation reactions using molecular oxygen failed. Stimulated by the high performance of ruthenium complexes in polyhalogenated porphyrins, ${ }^{8,9,13}$ we next studied the catalytic activity of carbonylruthenium (tetrakispentafluorophenyl)porphyrin $\mathrm{Ru}(\mathrm{TPFPP})(\mathrm{CO}) \mathbf{1}$ for the homogeneous

a Department of Chemistry, University of North Carolina at Chapel Hill, Chapel Hill, NC, 27599-3290, USA. E-mail:mgagne@unc.edu

${ }^{b}$ Institut des Sciences et Ingénieries Chimiques, École Polytechnique Fédérale de Lausanne (EPFL), 1015, Lausanne, Switzerland aerobic oxidation of alcohols. The stability of these halogenated derivatives to oxidative destruction and their modified redox potentials were properties that we hoped would successfully overcome the inactivity of the $1^{\text {st }}$-generation catalyst. In this article we outline our efforts to discover an active aerobic oxidation catalyst, with an emphasis on deconvoluting the role of ruthenium-catalyzed and autooxidation pathways. We document experimental conditions under which either (and likely both) mechanisms contribute to a highly efficient oxidation (quantitative oxidation was documented at $0.01 \mathrm{~mol} \%$ ruthenium loading).

The catalytic activity of $\mathbf{1}$ was examined for the aerobic oxidation of benzhydrol $\mathbf{3}$ to benzophenone $\mathbf{4}$ in various solvents under an $\mathrm{O}_{2}$ atmosphere ( $1 \mathrm{~atm}$ ) at different temperatures (Table 1). The conversion of $\mathbf{3}$ to $\mathbf{4}$ was monitored by ${ }^{1} \mathrm{H}$ NMR of the reaction mixture using tert-butylbenzene as an internal standard. Complex 1 itself was almost inactive at $60{ }^{\circ} \mathrm{C}$ until oxidized to the dioxoruthenium form $\mathbf{2}$ (entry 1). Complex 2 was prepared in situ by oxidation of 1 with two equivalents of meta-chloroperbenzoic acid (mCPBA) at $60{ }^{\circ} \mathrm{C}$ and used without isolation (eqn 1). ${ }^{14}$

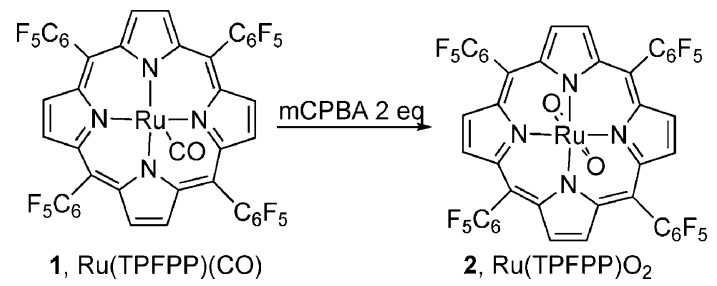

The choice of solvent was essential to the activity of the catalyst. Hirobe $^{8}$ and later Iida $^{15}$ reported that the mineral acids $\mathrm{HCl}$ and $\mathrm{HBr}$ could be used to enhance the activity of ruthenium porphyrin complexes, presumably by forming more active halo-ruthenium porphyrin complexes. Dihalogen ruthenium porphyrins can also be prepared from carbonyl ruthenium precursors by reaction with $\mathrm{CCl}_{4}$ or $\mathrm{CBr}_{4} \cdot{ }^{9 b, 16}$ Che has improved the catalytic activity of ruthenium carbonyl porphyrin by first refluxing in $\mathrm{CCl}_{4} \cdot{ }^{17}$ In this contribution we report that $\mathrm{CBrCl}_{3}$ may also be used as a soft non-acidic activator and solvent and that it can improve the activation of the ruthenium porphyrin complex; nonacidic activators being especially important for the oxidation of 
Table 1 Optimization of the catalytic system

\begin{tabular}{|c|c|c|c|c|c|}
\hline Entry & Catalyst & Solvent/additives & Temperature $/{ }^{\circ} \mathrm{C}$ & Time/h & Yield of $4(\%)^{a}$ \\
\hline 1 & 1 & $\mathrm{CBrCl}_{3}$ & 60 & 18 & 4 \\
\hline 2 & $2^{b}$ & $\mathrm{CCl}_{4}$ & 60 & 4 & 1.5 \\
\hline 3 & $2^{b}$ & $\mathrm{CD}_{3} \mathrm{CN}$ & 60 & 4 & 2 \\
\hline 4 & $2^{b}$ & $\mathrm{PhCl}$ & 100 & 4 & 4 \\
\hline 5 & $2^{b}$ & $\mathrm{C}_{4} \mathrm{~F}_{9} \mathrm{OMe}-\mathrm{CBrCl}_{3}(9: 1, \mathrm{v} / \mathrm{v})$ & 60 & 4 & $<1$ \\
\hline 6 & $\mathbf{2}^{b}$ & $\mathrm{CBrCl}_{3}$ & 60 & 3 & 10 \\
\hline $7^{c}$ & $\mathbf{2}^{b}$ & $\mathrm{CBrCl}_{3}$ & 80 & 22 & 31 \\
\hline $8^{c}$ & $2^{b}$ & $\mathrm{CBrCl}_{3}$ & 100 & 18 & 74 \\
\hline $9^{d}$ & $2^{b}$ & $\mathrm{CBrCl}_{3}-\mathrm{D}_{2} \mathrm{O}-\mathrm{NaOD}\left(250 \mathrm{~mol}^{\%} \%\right)$ & 90 & 4 & 63 \\
\hline $10^{d}$ & $2^{b}$ & $\mathrm{CBrCl}_{3}-\mathrm{D}_{2} \mathrm{O}-\mathrm{NaOD}\left(250 \mathrm{~mol}^{\circ} \%\right)$ & 100 & 3 & 30 \\
\hline 11 & $\mathbf{2}^{b}$ & $\mathrm{CBrCl}_{3}-\mathrm{H}_{2} \mathrm{O}-\mathrm{Bu}_{4} \mathrm{NOH}(25 \mathrm{~mol} \%)$ & 90 & 24 & 99 \\
\hline 12 & 1 & $\mathrm{CBrCl}_{3}-\mathrm{H}_{2} \mathrm{O}-\mathrm{Bu}_{4} \mathrm{NOH}(25 \mathrm{~mol} \%)$ & 90 & 24 & 96 \\
\hline 13 & (TPFPP) $\mathrm{H}_{2}+$ mCPBA & $\mathrm{CBrCl}_{3}-\mathrm{H}_{2} \mathrm{O}-\mathrm{Bu}_{4} \mathrm{NOH}(25 \mathrm{~mol} \%)$ & 90 & 24 & 22 \\
\hline 14 & $\mathrm{Fe}(\mathrm{TPFPP}) \mathrm{Cl}+\mathrm{mCPBA}$ & $\mathrm{CBrCl}_{3}-\mathrm{H}_{2} \mathrm{O}-\mathrm{Bu}_{4} \mathrm{NOH}(25 \mathrm{~mol} \%)$ & 90 & 24 & 66 \\
\hline
\end{tabular}

${ }^{a}$ Determined by ${ }^{1} \mathrm{H}$ NMR, internal standard tert-butylbenzene, $\mathrm{S} / \mathrm{C}$ ratio $=100 .{ }^{b}$ Catalyst 2 prepared in situ from $1 .{ }^{c}$ Conversion was accompanied by the side products 5, 6, and $7 .{ }^{d}$ Reaction stopped after destruction of ruthenium porphyrin.

acid-sensitive compounds. Of the studied solvents (Table 1, entries 2-6), only $\mathrm{CBrCl}_{3}$ provided significant oxidation of 3 .

The combination of $\mathrm{CBrCl}_{3}$ and 2 was nearly inert without $\mathrm{O}_{2}$, as demonstrated by heating 3 with $\mathrm{CBrCl}_{3}$ and catalyst 2 at $100{ }^{\circ} \mathrm{C}$ under argon. Analysis after $20 \mathrm{~h}$ showed a $4 \%$ conversion to benzophenone, which could be attributed to stoichiometric oxidation of 3 with dioxoruthenium complex 2. Catalytic oxidations of $\mathbf{3}$ to $\mathbf{4}$ in $\mathrm{CBrCl}_{3}$, however, were accompanied by significant amounts of the undesirable 5, 6 and 7 (eqn 2). ${ }^{18}$ Higher temperatures accelerated the oxidation (Table 1, entries 6-8) but also increased the proportion of side products. These compounds could be suppressed with an inorganic base (entries 9 and 10), but at the cost of accelerated catalyst destruction. Catalyst longevity could be recovered by adding an aqueous solution of $\mathrm{Bu}_{4} \mathrm{NOH}$ ( $25 \mathrm{~mol}^{\%} \%$ to 3) to act as a phase transfer reagent and base. Under these optimum conditions the selectivity increased to 99\% (entry 11 ), and 1 did not need preactivation with mCPBA to be effective (entry 12). Free porphyrin ligand (TPFPP) $\mathrm{H}_{2}$ and iron porphyrin complex Fe(TPFPP)Cl are also catalytically active (entries 13 and 14), but observed conversions of 3 are less than for the ruthenium catalyst.

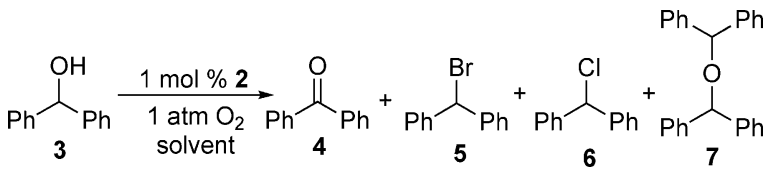

As shown in Fig. 1, the progression of the oxidation was investigated at different loadings of catalyst. In each case an induction period was observed and a relatively constant growth of benzophenone ensued.

The viability of an autooxidation process was investigated by similarly following the reaction in the absence of catalyst (see Table 2). In this manner it was established that over the first $24 \mathrm{~h}$ period, the autooxidation was much slower $(6 \%$ conversion) than with ruthenium (Fig. 1, entry 1 in Table 2). When this same reaction was quantified after $65 \mathrm{~h}$, however, complete oxidation had occurred (entry 1). The autocatalytic nature of this oxidation was traced to a benzophenone-mediated photo-autooxidation under normal fumehood light (entry 2). It was additionally established that the autooxidation was almost

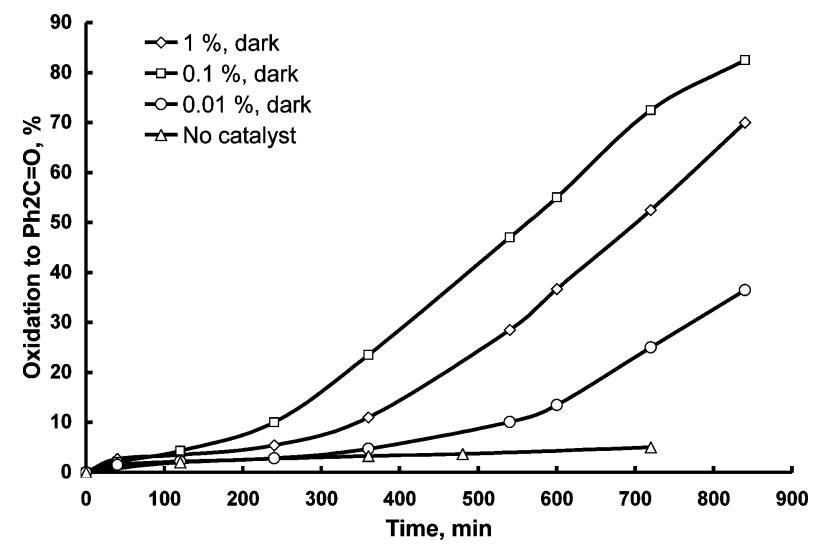

Fig. 1 Oxidation of 3 to 4 with different S/C ratios.

completely suppressed ( $7 \%$ conversion at $48 \mathrm{~h}$ ) in the dark even with added benzophenone (entry 3 ). Repeating catalytic reactions under the optimum conditions, but wrapped in foil, indicated that the ruthenium-mediated oxidation was insensitive to light (entries 4 and 5). BHT (2,6-di-tert-butyl-4-methylphenol) also effectively terminated the autooxidation pathway (entry 6), while it only inhibited the ruthenium-catalyzed oxidation (entry 7). The outcome of these experiments were thus consistent with a scenario wherein ruthenium-catalyzed oxidation occurs in parallel with, and perhaps independent of, a radical chain autooxidation that does not take place in the dark or in the presence of a radical trap. Conditions could be engineered to exclude the autooxidation pathway but under typical conditions it seems, at least for the photo sensitizer benzophenone, that both pathways occur to some degree.

This optimized catalytic system (Table 2, footnote $a$ ) was used in the oxidation of a set of secondary alcohols (Table 3 ). To evaluate the maximal turnover number (TON), experiments with decreasing catalyst concentration (higher substrate to catalyst ratio, $\mathrm{S} / \mathrm{C}$ ) were carried out. With a S/C ratio of 10000 , an $82 \%$ yield was achieved for benzhydrol 3; even higher yields were observed for 8 and 10. The corresponding ketones 4, 9, and 11 were isolated in high yields. 4,4'-Dimethoxybenzhydrol 12 also oxidized to the ketone $\mathbf{1 3}$ in good yield; however, the oxidation was complicated 
Table 2 Control experiments outlining the role of autoxidation pathways

\begin{tabular}{|c|c|c|c|c|}
\hline Entry & Catalyst & Conditions $^{a}$ & Time/h & Yield of $4(\%)^{b}$ \\
\hline 1 & None & Standard & $\begin{array}{l}24 \\
65\end{array}$ & $\begin{array}{l}6 \\
99\end{array}$ \\
\hline 2 & None & Standard $+25 \mathrm{~mol} \% \mathrm{Ph}_{2} \mathrm{CO}$ & 12 & 100 \\
\hline 3 & None & Standard $+25 \mathrm{~mol} \% \mathrm{Ph}_{2} \mathrm{CO}$, dark & 48 & 7 \\
\hline 4 & $2^{c, d}$ & Standard & 20 & 92 \\
\hline 5 & $2^{c, d}$ & Dark & 24 & 82 \\
\hline 6 & None & Dark $+10 \mathrm{~mol} \%$ BHT & 72 & NR \\
\hline 7 & $2^{c}$ & Dark $+10 \mathrm{~mol} \%$ BHT & 24 & 61 \\
\hline
\end{tabular}

${ }^{a}$ All reactions were performed with the standard conditions $\left(0.2 \mathrm{mmol}\right.$ of $3,10 \mathrm{~mL}$ of $\mathrm{CBrCl}_{3}, 0.05 \mathrm{~mL}$ of $1 \mathrm{M}$ aqueous solution of Bu $\mathrm{NOH}^{\circ}$ at $90{ }^{\circ} \mathrm{C}$. ${ }^{b}$ Determined by ${ }^{1} \mathrm{H}$ NMR, internal standard tert-butylbenzene. ${ }^{c}$ Catalyst 2 was prepared in situ from $1 .{ }^{d} \mathrm{~S} / \mathrm{C}=10000$.

Table 3 Oxidation of alcohols in the $\mathrm{CBrCl}_{3}-\mathrm{Bu}_{4} \mathrm{NOH}$ system ${ }^{a}$

\begin{tabular}{|c|c|c|c|c|}
\hline Entry & Substrate & $\mathrm{S} / \mathrm{C}$ & Yield of ketone $(\%)^{b}$ & Product \\
\hline 1 & 3 & 100 & 95 & 4 \\
\hline 2 & 3 & 1000 & $99\left(97^{c}\right)$ & 4 \\
\hline 4 & $\mathrm{OH}$ & 1000 & $95\left(92^{c}\right)$ & 0 \\
\hline & 8 & & & 9 \\
\hline 5 & 8 & 10000 & 99 & 9 \\
\hline 6 & $\mathrm{OH}$ & 1000 & $99\left(98^{c}\right)$ & 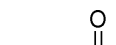 \\
\hline & 10 & & & 11 \\
\hline
\end{tabular}

${ }^{a}$ Alcohol $(200 \mu \mathrm{mol})$, catalyst $2, \mathrm{CBrCl}_{3}(10 \mathrm{~mL}), \mathrm{Bu}_{4} \mathrm{NOH} 1 \mathrm{M}$ aqueous solution $(0.05 \mathrm{~mL}), 90{ }^{\circ} \mathrm{C}, 24 \mathrm{~h} .{ }^{b}$ Determined by ${ }^{1} \mathrm{H}$ NMR, internal standard tert-butylbenzene. ${ }^{c}$ Isolated yield.

by the formation of unidentified side products. Oxidation of other alcohols - 1-phenylethanol and benzyl alcohol - resulted in complex product mixtures.

In addition to the above $\mathrm{CBrCl}_{3}$ activation approach, we sought reaction conditions that might be less susceptible to autooxidation pathways. Cognizant of the safety risks of hydrocarbon-based solvents and knowing that highly fluorinated solvents have high oxygen solubility (as well as being non-flammable), ${ }^{19}$ we developed alternative conditions based on the relatively high boiling (137$160{ }^{\circ} \mathrm{C}$ ) perfluoro(methyldecalin) PFMD. Like numerous fluorinated solvents, PFMD is immiscible with regular organic solvents at room temperature and miscible at elevated temperatures, thus facilitating the separation of products and the recovery of the fluorous solvent. ${ }^{19}$ As before, the catalytic activity of $\mathbf{2}$ was investigated with alcohol 3. Table 4 collects the data showing that the catalytic activity of $\mathbf{2}$ was dependent on both reaction temperature and oxygen pressure. Expressed as a TON (initial $\mathrm{S} / \mathrm{C}=100$ ), the conversion of $\mathbf{3}$ to $\mathbf{4}$ increased as the oxygen pressure was increased from 12.5 to 25 to 50 psi (TONs 9, 28, and 45 , respectively). Increasing the temperature from 120 to
Table 4 Oxidation of alcohol 3 by oxygen in PFMD solvent

\begin{tabular}{lllll}
\hline Entry & Catalyst $^{a}$ & $\mathrm{O}_{2}$ pressure/psi & Temp. $/{ }^{\circ} \mathrm{C}$ & TON to 4 \\
\hline 1 & $\mathbf{2}$ & 12.5 & 140 & 9 \\
2 & $\mathbf{2}$ & 25 & 140 & 28 \\
3 & $\mathbf{2}$ & 50 & 140 & 45 \\
4 & $\mathbf{2}$ & 50 & 160 & 42 \\
5 & $\mathbf{2}$ & 50 & 120 & 15 \\
6 & $\mathbf{1}$ & 50 & 140 & 12 \\
7 & None & 50 & 140 & $-^{b}$ \\
$8^{c}$ & $\mathbf{2}$ & 50 & 140 & 35 \\
$9^{d}$ & $\mathbf{2}$ & 50 & 140 & 27 \\
$10^{e}$ & $\mathbf{2}$ & 50 & 140 & 15
\end{tabular}

${ }^{a}$ Catalyst 2 was prepared in situ from $1 .{ }^{b}$ Only ether 7 was isolated. ${ }^{c}$ Benzophenone $(10 \mathrm{~mol} \%)$ was added. ${ }^{d}$ BHT $(10 \mathrm{~mol} \%)$ was added. ${ }^{e}$ Reaction was carried out in the dark.

$140{ }^{\circ} \mathrm{C}$ tripled the yield of ketone, but additional increases were not beneficial. Under optimum conditions $\left(140^{\circ} \mathrm{C}, 50 \mathrm{psi}\right.$ of $\left.\mathrm{O}_{2}\right)$, the unactivated ruthenium carbonyl catalyst 1 could be directly used, but it was less effective (entry 6). 
Table 5 Oxidation of alcohols in the PFMD system ${ }^{a}$

\begin{tabular}{llll}
\hline Entry & Substrate & TON $^{b}$ & Product \\
\hline 1 & $\mathbf{3}$ & 45 & $\mathbf{4}$ \\
2 & $\mathbf{8}$ & 99 & $\mathbf{9}$ \\
3 & $\mathbf{1 0}$ & 42 & $\mathbf{1 1}$ \\
4 & $\mathbf{1 2}$ & 68 & $\mathbf{1 3}$
\end{tabular}

${ }^{a}$ Alcohol $(200 \mu \mathrm{mol})$, catalyst $2(2 \mu \mathrm{mol}, \mathrm{S} / \mathrm{C}=100)$, PFMD $(5 \mathrm{~mL})$, $\mathrm{O}_{2}(50 \mathrm{psi}), 140{ }^{\circ} \mathrm{C}, 24 \mathrm{~h} .{ }^{b}$ Determined by ${ }^{1} \mathrm{H}$ NMR, internal standard tert-butylbenzene.

An important component of reaction efficiency was a concurrent condensation process that converted $\mathbf{3}$ into tetraphenyldimethyl ether 7. In fact, only $\mathbf{7}$ and $\mathbf{4}$ were observed at the completion of the reaction. This thermal process converts the more reactive substrate into one that is considerably less so, as demonstrated by oxidation reactions of the isolated ether 7 $(12 \%$ conversion after $24 \mathrm{~h})$. The condensation occurs quickly in the absence of catalyst $\left(<3 \mathrm{~h}\right.$ at $\left.140{ }^{\circ} \mathrm{C}\right)$. Hypothesizing that accelerating the reverse hydration process might lead to a more efficient oxidation process, the reaction was repeated with added water, and a slight inhibition was observed $(28 \%$ of 4 after $24 \mathrm{~h}$ ); the high temperatures almost certainly help to drive the dehydration. As described above, it was established that $\mathbf{3}$ quantitatively converted to 7 under heating without catalyst (entry 7); and most importantly no autooxidation was observed. Since addition of benzophenone did not accelerate oxidation (entry 8 ), and reactions in the dark or in the presence of BHT were only slowed (entries 9,10 ), we propose a metal-catalyzed aerobic oxidation under these conditions.

To evaluate the scope of this variant on the catalytic system, we investigated the oxidation of a number of alcohols (Table 5). Non-enolizable alcohols $\mathbf{3}, \mathbf{8}, \mathbf{1 0}$, and $\mathbf{1 2}$ were smoothly oxidized to their corresponding ketones, fluorenol $\mathbf{8}$ being particularly well behaved (entry 2). It is worth noting that no dimer analogous to 7 was observed with the other alcohols, and unreacted alcohol was observed in these cases. Oxidation of other alcohols - 1phenylethanol and benzyl alcohol - resulted in the formation of multiple products, although corresponding carbonyl compounds were detected by ${ }^{1} \mathrm{H}$ NMR. For example, benzaldehyde and benzoic acid (along with other unidentified products) were observed for benzyl alcohol.

\section{Conclusions}

In summary, we report that the combination of 2 with $25 \mathrm{~mol} \%$ $\mathrm{Bu}_{4} \mathrm{NOH}$ in $\mathrm{CBrCl}_{3}$ effectively oxidizes secondary alcohols to ketones in good to excellent yields with molecular oxygen. Control experiments indicated that under the optimum reaction conditions ruthenium catalysis and autooxidation were both viable, though conditions could be engineered (radical traps or absence of light) wherein the autooxidation pathway was shut down and only ruthenium catalysis converted alcohol to ketone, high turnover efficiencies being achieved. Alternatively, these alcohols could be oxidized using 2 and oxygen in a fluorinated solvent (PFMD). Numerous control experiments suggested that autooxidation did not occur under these modified conditions.

\section{Experimental}

\section{General}

The synthesis of complex 1 was performed as described. ${ }^{9 b}$ metaChloroperbenzoic acid (mCPBA, 77\%, Aldrich) was used without purification. Perfluoro(methyldecalin) (PFMD, 80\%, Aldrich) was degassed by a standard freeze-pump-thaw procedure and saturated with oxygen prior to use. The identity of the product ketones were confirmed by comparison with commercially available compounds. ${ }^{1} \mathrm{H}$ NMR analyses were performed on a Bruker $400 \mathrm{MHz}$ AVANCE spectrometer. The UV analyses were performed with Hewlett Packard 8453 UV-Visible spectrometer.

\section{In situ activation of ruthenium carbonyl porphyrin complex 1}

Complex 1 (2.2 mg, $2 \mu \mathrm{mol})$ was first dissolved in $\mathrm{CBrCl}_{3}(5 \mathrm{~mL})$ at $60{ }^{\circ} \mathrm{C}$ (oil bath), and then mCPBA $(0.9 \mathrm{mg}, 4 \mu \mathrm{mol})$ was added in one portion to the solution. At $60{ }^{\circ} \mathrm{C}$ complete oxidation of 1 to dioxoruthenium complex 2 required only a few seconds. The oxidation could be monitored by UV/Vis or more routinely by the color change from crimson to brown. The solution of $\mathbf{2}$ was used within 1 hour of preparation.

\section{General procedure for the oxidation of alcohols in $\mathrm{CBrCl}_{3}$}

To a catalyst solution, containing $2 \mu \mathrm{mol}(\mathrm{S} / \mathrm{C}$ ratio $=100), 0.2$ $\mu \mathrm{mol}(\mathrm{S} / \mathrm{C}$ ratio $=1000)$ or $0.02 \mu \mathrm{mol}(\mathrm{S} / \mathrm{C}$ ratio $=10000)$ of 2 in $\mathrm{CBrCl}_{3}(10 \mathrm{~mL})$, prepared by dilution of the stock solution (see above), was added an aqueous solution of tetrabutylammonium hydroxide (50 $\mu \mathrm{mol}, 50 \mu \mathrm{L}$ of a $1 \mathrm{M}$ solution) and substrate $(200 \mu \mathrm{mol})$. Oxygen was bubbled through the reaction mixture for 15 min while heating to $90{ }^{\circ} \mathrm{C}$. The mixture was stirred at $90{ }^{\circ} \mathrm{C}$ for $24 \mathrm{~h}$ under an oxygen atmosphere (1 atm). After complete consumption of starting material, the reaction mixture was cooled to rt, concentrated under vacuum and chromatographed (hexanes-EtOAc) to give the ketone.

\section{General procedure for the oxidation of alcohols in perfluoro(methyldecalin)}

A catalyst solution, containing $2 \mu \mathrm{mol}$ of 2 in chloroform $(0.2 \mathrm{~mL}$, prepared as described above) was added to a high pressure glass reaction vessel equipped with a pressure gauge, and diluted with PFMD $(5 \mathrm{~mL})$. Alcohol $(200 \mu \mathrm{mol}, \mathrm{S} / \mathrm{C}$ ratio $=100)$ was added in one portion, and the reaction vessel was then filled with oxygen (50 psi) and heated to $140{ }^{\circ} \mathrm{C}$ (oil bath). Once $140{ }^{\circ} \mathrm{C}$ was achieved, the pressure was then released and the vessel was refilled with oxygen. The reaction mixture was stirred at $140{ }^{\circ} \mathrm{C}$ under oxygen for $24 \mathrm{~h}$, the pressure was then released and the reaction mixture cooled to room temperature. The organics were extracted with $\mathrm{CDCl}_{3}(2 \times$ $1 \mathrm{~mL}$ ) and the mixture analyzed by ${ }^{1} \mathrm{H}$ NMR.

\section{Acknowledgements}

We gratefully acknowledge the Army Research Office (Grant \# W911NF0510081) and the Defense Threat Reduction Agency (DTRA) for funding. KS thanks the Swiss National Science Foundation and the EPFL for kind support. 


\section{References}

1 Modern Oxidation Methods, ed. J.-E. Bäckvall, Wiley-VCH, Weinheim, 2004.

2 For general reviews, see: (a) R. A. Sheldon and I. W. C. E. Arends, 'Catalytic oxidations of alcohols', in Advances in Catalytic Activation of Dioxygen by Metal Complexes, ed. L. I. Simándi, Kluwer Academic Publishers, London, 2003, pp. 123-155; (b) I. W. C. E. Arends and R. A. Sheldon, 'Modern oxidation of alcohols using environmentally benign oxidants', in Modern Oxidation Methods, ed. J.-E. Bäckvall, WileyVCH, Weinheim, 2004, pp. 83-118; (c) I. E. Markó, P. R. Giles, M. Tsukazaki, A. Gautier, R. Dumeunier, K. Doda, F. Philippart, I. ChelléRegnault, J.-L. Mutonkole, S. M. Brown and C. J. Urch, Aerobic, metal-catalyzed oxidation of alcohols', in Transition Metals for Organic Synthesis ( $2^{\text {nd }}$ edn), ed. M. Beller and C. Bolm, Wiley-VCH, Weinheim, 2004, pp. 437-478; (d) B.-Z. Zhan and A. Thompson, Tetrahedron, 2004, 60, 2917-2935; (e) T. Mallat and A. Baiker, Chem. Rev., 2004, 104, 3037-3058; $(f)$ M. J. Schultz and M. S. Sigman, Tetrahedron, 2006, 62, 8227-8241; $(g)$ M. S. Sigman and D. R. Jensen, Acc. Chem. Res., 2006, 39, 221-229.

3 For Ru-catalyzed aerobic oxidations, see: (a) B. R. James, 'Selective oxidations with dioxygen catalyzed by ruthenium and rhodium complexes', in Dioxygen Activation and Homogeneous Catalytic Oxidation, ed. L. I. Simándi, Elsevier, Amsterdam, 1991, pp. 195-212; (b) T. Naota, H. Takaya and S.-I. Murahashi, Chem. Rev., 1998, 98, 2599-2660; (c) M. Pagliaro, S. Campestrini and R. Ciriminna, Chem. Soc. Rev., 2005, 34, $837-845$.

4 (a) I. E. Markó, P. R. Giles, M. Tsukazaki, I. Chellé-Regnault, C. J. Urch and S. M. Brown, J. Am. Chem. Soc., 1997, 119, 12661-12662; (b) N. Komiya, T. Nakae, H. Sato and T. Naota, Chem. Commun., 2006, 4829-4831; (c) F. Shi, M. K. Tse and M. Beller, Chem.-Asian J., 2007, 2, 411-415.

5 For the application of heterogeneous ruthenium catalysts in aerobic oxidation of alcohols, see: (a) K. Yamaguchi and N. Mizuno, Angew. Chem., Int. Ed., 2002, 41, 4538-4542; (b) K. Yamaguchi and N. Mizuno, Chem.-Eur. J., 2003, 9, 4353-4361; (c) H.-Y. Shen, S.-C. Zhou, M.-H. Wei and H.-X. Zong, React. Funct. Polym., 2006, 66, 827-831; (d) T. Matsumoto, M. Ueno, J. Kobayashi, H. Miyamura, Y. Mori and S. Kobayashi, Adv. Synth. Catal., 2007, 349, 531-534.

6 J. T. Groves and R. Quinn, J. Am. Chem. Soc., 1985, 107, 5790-5792.

7 For the reviews of ruthenium porphyrin catalyzed oxidations, see: (a) B. Meunier, Chem. Rev., 1992, 92, 1411-1456; (b) T. Mlodnicka and B. R. James, 'Oxidations Catalyzed by Ruthenium Porphyrins', in Metalloporphyrins Catalyzed Oxidations, ed. F. Montanari and L. Casella, Kluwer Academic Publishers, London, 1994, pp. 121-148; (c) J. T. Groves, K. Shalyaev and J. Lee, 'Oxometalloporphyrins in oxidative catalysis', in The Porphyrin Handbook, Vol. 4, ed. K. Kadish, K. Smith and R. Guilard), Academic Press, New York, 2000, pp. 17-40; (d) M. B. Ezhova and B. R. James, 'Catalytic oxidation using ruthenium porphyrins', in Advances in Catalytic Activation of Dioxygen by Metal Complexes, ed. L. I. Simándi, Kluwer Academic Publishers, London, 2003, pp. 1-77.

8 (a) T. Higuchi, H. Ohtake and M. Hirobe, Tetrahedron Lett., 1989, 30, 6545-6548; (b) T. Higuchi, H. Ohtake and M. Hirobe, Tetrahedron Lett., 1991, 32, 7435-7438; (c) H. Ohtake, T. Higuchi and M. Hirobe, J. Am. Chem. Soc., 1992, 114, 10660-10662; (d) H. Ohtake, T. Higuchi and M. Hirobe, Tetrahedron Lett., 1992, 33, 2521-2524; (e) H. Ohtake, T. Higuchi and M. Hirobe, Heterocycles, 1995, 40, 867-903; $(f) \mathrm{T}$. Higuchi and M. Hirobe, J. Mol. Catal. A: Chem., 1996, 113, 403422 .

9 (a) J. T. Groves, M. Bonchio, T. Carofiglio and K. Shalyaev, J. Am. Chem. Soc., 1996, 118, 8961-8962; (b) C. Wang, K. V. Shalyaev, M. Bonchio, T. Carofiglio and J. T. Groves, Inorg. Chem., 2006, 45, 47694782.

10 TONs of about 1.5 per day have been realized for oxidation of isopropanol: S. Y. S. Cheng, N. Rajapakse, S. J. Rettig and B. R. James, J. Chem. Soc., Chem. Commun., 1994, 2669-2670.

11 The aerobic oxidation of alcohols in the presence of a sacrificial reductant and a ruthenium porphyrin catalyst has been reported: H.-B. Ji, Q.-L. Yuan, X.-T. Zhou, L.-X. Pei and L.-F. Wang, Bioorg. Med. Chem. Lett., 2007, 17, 6364-6368. See also: M. T. Zhou, H.-B. Ji, Q.-L. Yuan, J. C. Xu, L. Y. Pei and L.-F. Wang, Chin. Chem. Lett., 2007, 18, 926-928.

12 (a) O. Nestler and K. Severin, Org. Lett., 2001, 3, 3907-3909; (b) E. Burri, M. Öhm, C. Daguenet and K. Severin, Chem.-Eur. J., 2005, 11, 5055-5061; (c) E. Burri, S. M. Leader, K. Severin and M. R. Gagné, Adv. Synth. Catal., 2006, 348, 1640-1644; (d) E. Burri and K. Severin, Chimia, 2006, 60, 182-184.

13 (a) S.-I. Murahashi, T. Naota and N. Komiya, Tetrahedron Lett., 1995, 36, 8059-8062; (b) E. R. Birnbaum, J. A. Labinger, J. E. Bercaw and H. B. Gray, Inorg. Chim. Acta, 1998, 270, 433-439.

14 Formation of $\mathbf{2}$ in the oxidation of $\mathbf{1}$ with mCPBA was described recently: see ref. $9 b$.

15 S. Ogawa, T. Iida, T. Goto, N. Mano, J. Goto and T. Nambara, Org. Biomol. Chem., 2004, 2, 1013-1018.

16 Z. Gross and C. M. Barzilay, J. Chem. Soc., Chem. Commun., 1995, $1287-1288$.

17 R. Zhang, W.-Y. Yu, K.-Y. Wong and C.-M. Che, J. Org. Chem., 2001, 66, 8145-8153.

18 The identity of compounds 5-7 was established by the comparison of their ${ }^{1} \mathrm{H}$ NMR spectra with literature data: (a) L. J. Stangeland and J. Songstad, Acta Chem. Scand., 1970, 24, 356-358; (b) K. J. Miller and M. M. Abu-Omar, Eur. J. Org. Chem., 2003, 1294-1299.

19 (a) Handbook of Fluorous Chemistry, ed. J. A. Gladysz, D. P. Curran and I. T. Horvath, Wiley-VCH, Weinheim, 2004; (b) E. P. Wesseler, R. Iltis and L. C. Clark, Jr., J. Fluorine Chem., 1977, 9, 137-146. 